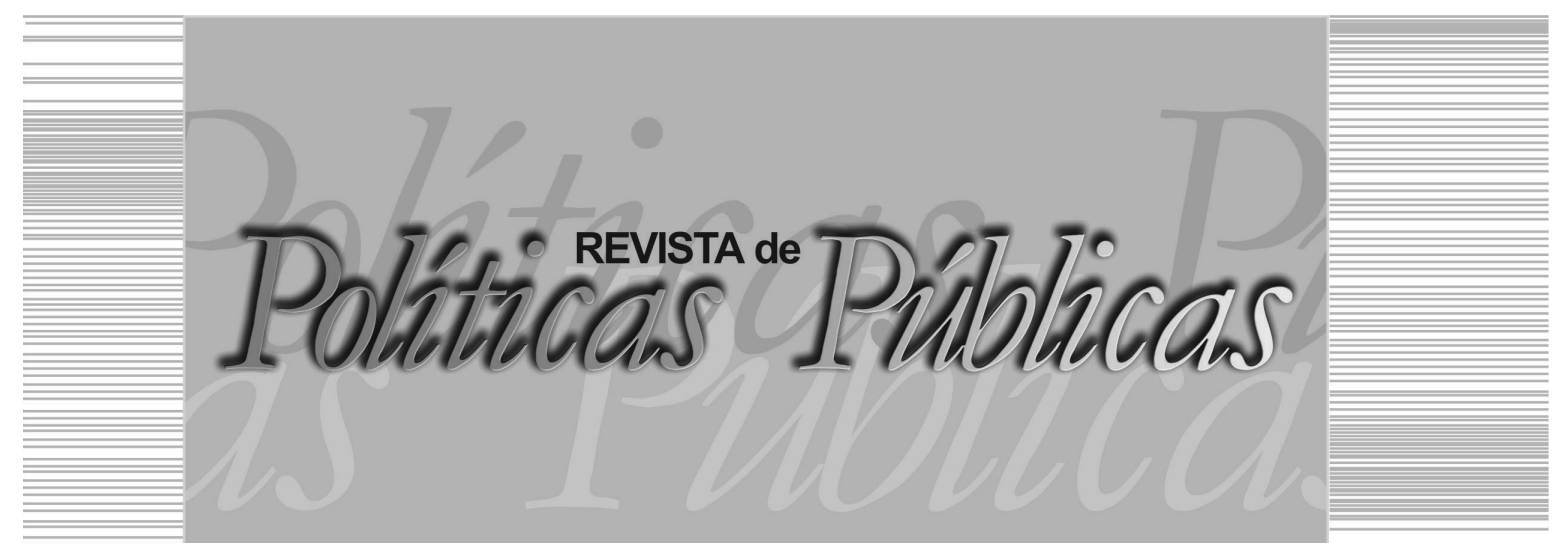

\title{
URBANIZAÇÃO EXTENSIVA NA AMAZÔNIA BRASILEIRA E FORMAÇÃO DO MOVIMENTO INDIGENA
}

\author{
Renata Guimarães Vieira \\ Universidade Federal de Minas Gerais (UFMG) \\ Ian Coelho de Souza Almeida ${ }^{2}$ \\ Universidade Federal de Minas Gerais (UFMG)
}

\section{Resumo}

Segundo o Instituto Socioambiental, hoje existem mais de 160 organizações indígenas somente no estado do Amazonas. Essas organizações representam uma forma de relação que anteriormente não fazia parte do cotidiano das comunidades indígenas. Este artigo, então, busca entendê-las como parte de um processo de chegada da lógica da cidade urbano-industrial, analisada a partir da Teoria da Urbanização Extensiva. No entanto, como esse processo ocorre de maneira complexa e não passiva, além de envolver diversos aspectos da vida indígena, o artigo utiliza, por exemplo, a ideia de uma diferenciação entre os modos de agir dentro e fora da política por parte dos indígenas, entendidos como duas culturas distintas. Desse modo, faz uma análise do processo histórico e do protagonismo dos indígenas nas lutas pelos direitos que entendem como seus, além de apontar dificuldades nos recentes retrocessos das políticas públicas.

Palavras-chave: Urbanização extensiva, movimentos indígenas, cultura.

\footnotetext{
Economista, Doutoranda em Economia pelo Centro de Desenvolvimento e Planejamento Regional (CEDEPLAR) da Universidade Federal de Minas Gerais (UFMG). E-mail: renataguivieira@gmail.com

2 Economista, Doutoranda em Economia pelo CEDEPLAR/UFMG. E-mail: iancsalmeida@ gmail.com / Universidade Federal de Minas Gerais - UFMG: Faculdade de Ciências Econômicas - $3^{\circ}$ Andar, Avenida Presidente Antônio Carlos, 6627 - Pampulha, Belo Horizonte - MG. CEP: 31270-901
} 


\title{
EXTENDED URBANIZATION IN BRAZILIAN AMAZON AND THE INDIGENOUS MOVEMENT CONSTITUTION
}

\begin{abstract}
According to the Instituto Socioambiental, there are more than 160 indigenous organizations nowadays in the state of Amazonas alone. These organizations represent a form of relationship that was previously unknown to the daily life of indigenous communities. In the present article, therefore, we intended to understand the organizations as part of a process of urban-industrial logic insertion. This was analyzed based on the Extensive Urbanization Theory. Nevertheless, for this process occurs in a non-passive and complex manner, besides involving several aspects of indigenous life, caution is required to deal with it. We resort, for example, to the idea of a differentiation between way of acting in front of political and non-political matters, understood as two different cultures. In this way, we were able to analyze the historical process and protagonism of indigenous in the struggle for the right that they see as theirs. Furthermore, we pinpoint some aspects of a difficult scenario ahead of those organizations in dealing with contemporary public policies.

Key words: Extended urbanization, indigenous movement, culture.
\end{abstract}

\section{INTRODUÇÃO}

Este trabalho tem o objetivo de entender o modo como surgiram os movimentos sociais indígenas no território brasileiro, relacionando-os à reprodução da lógica urbana em todo o território nacional. O surgimento e fortalecimento desses movimentos, assim como das demais organizações indígenas (e indigenistas $\left.{ }^{1}\right)$ são, antes de mais nada, respostas às experiências de desrespeito. Estas, segundo Bittencourt (2000), estão relacionadas às ações do Estado que ignoraram aquilo que os indígenas entendem como seus direitos e territórios. Tais experiências de desrespeito são o que Bicalho (2010b), com base no trabalho de Axel Honnet (2003), aponta como impulsionadoras do protagonismo indígena em sua luta por reconhecimento.

A sistemática abertura de estradas e o avanço das telecomunicações, por exemplo, impactam de maneira irreversível a vida dos povos indígenas e os coloca em contato com a política do resto do país. (BITTENCOURT, 2000). Nesse sentido, o Estado desenvolvimentista e as políticas de interiorização, os quais ganharam um fôlego durante o período militar, são aspectos cruciais no entendimento das reações dos povos indígenas. O início dos anos 1970 é 
apontado por Bittencourt (2000) como o despertar do movimento indígena enquanto um movimento social organizado ${ }^{2}$. No entanto, neste primeiro momento, os movimentos pelos direitos indígenas são de caráter marcadamente indigenista, passando a ter o próprio indígena como principal protagonista apenas a partir dos anos 2000. (BICALHO, 2010b).

O avanço dos empreendimentos capitalistas, através de ações do Estado, pode ser entendido enquanto uma primeira etapa da expansão da lógica da cidade industrial, segundo um processo que Roberto Monte-Mór (2006) denomina Urbanização Extensiva. Essa abordagem, que será tratada em detalhe na próxima seção, compreende ainda outro momento de expansão. Neste, os mecanismos políticos característicos do meio urbano dos quais os movimentos sociais são parte, enquanto o outro é o espaço da festa, que não será discutido aqui. Sendo assim, buscamos tratar a forma como essas reações às experiências de desrespeito ocorreram, ligando-as a um movimento mais amplo de expansão do urbano.

A chegada de um novo modo de relações trazido pela expansão do urbano não é transportado integralmente e sem conflitos para a realidade das comunidades indígenas. Por isso, a terceira seção deste artigo se encarrega de discutir algumas das contradições geradas, utilizando, por exemplo, a noção de cultura e cultura de Manuela Carneiro da Cunha (2009), enquanto diferentes modos de agir dentro e fora da esfera política. Por fim, ao longo do texto também são tratados os diferentes modos com que se dá a relação política entre as comunidades e o Estado, principalmente no que diz respeito ao protagonismo do índio nesse processo.

O avanço do Estado capitalista sobre a terra e sobre a identidade de comunidades não urbanas não é uma exclusividade dos povos indígenas, mas também do campesinato e de povos quilombolas, como discutido em Silva (2013). No entanto, focaremos no primeiro grupo com o intuito de compreendermos a dinâmica de seu movimento político, o qual teve um crescimento significativo no final da década de 1980.

\section{URBANIZAÇÃO EXTENSIVA E O MOVIMENTO INDÍGENA}

O processo de subdesenvolvimento continuamente reproduzido nos países latino-americanos, descrito por Furtado (1974, 
2000), já foi extensamente debatido e dispensa maiores apresentações. Sabe-se que este processo é repleto de lacunas espaciais, temporais, tecnológicas, estruturais, relacionais. Disso resulta uma modernização incompleta e descontínua, uma mistura de elementos do passado e do presente, em constante diálogo com o futuro. Essa questão é ainda mais importante se consideramos o momento em que a lógica industrial explode, extrapolando os limites dos centros urbanos, atingindo todo, ou quase todo o território.

Essa explosão, no Brasil, ocorre a partir de meados de 1960, intensificando-se nas décadas de 1970 e 1980, e é sintetizado por Monte-Mór (2006) através da noção de urbanização extensiva. Conforme explica o autor, espalham-se pelo território as condições gerais de produção e reprodução próprias do capitalismo industrial, além de estruturas e serviços urbanos, direitos de cidadania, leis, transportes, sistemas de comunicação. $\mathrm{O}$ autor explica que, a partir da fase do capitalismo industrial,

\begin{abstract}
[a] cidade, lócus do excedente, do poder e da festa, cenário privilegiado da reprodução social, ficou assim subordinada à logica da indústria. A cidade sofreu então um duplo processo: sua centralidade implodiu sobre si mesma e sua periferia explodiu sobre o entorno sob a forma de tecido urbano, que acabou por carregar consigo o germe da polis e da civitas ${ }^{3}$. Assim, a práxis urbana, antes restrita à cidade, re-politizou todo o espaço social [...] No Brasil, o urbano teve sua origem na política ao mesmo tempo concentradora e integradora dos governos militares que deram sequencia à centralização e expansionismo Varguista e interiorização desenvolvimentista Juscelinista. Hoje, o urbano-industrial se impõe virtualmente a todo o espaço social, na urbanização extensiva dos nossos dias. (MONTE-MÓR, 2006, p. 5).
\end{abstract}

Como coloca Roberto Monte-Mór (2006), essa explosão, que expande o tecido urbano a áreas cada vez mais longínquas, leva consigo as condições de produção capitalistas segundo as necessidades de produção e reprodução da força de trabalho. Até então essas características eram exclusivas da cidade (cidade industrial), entendidas como o resultado de uma cada vez mais profunda divisão social do trabalho. Nesse aspecto, a imposição à cidade da lógica industrial, da produção, a torna um espaço privilegiado para o excedente econômico, e acaba por se estender para suas áreas periféricas a fim de acomodar a indústria e a mão-de-obra. Esse novo espaço urbanizado, industrial, passa a demandar do estado suas condições de 
produção, e também as condições de reprodução coletiva da força de trabalho. (MONTE-MÓR, 2006).

$\mathrm{O}$ autor chama de urbanização extensiva esse processo que leva através do tecido urbano as condições de produção industrial capitalista, que alcança todo o espaço social e aprofunda a integração social e espacial entre o urbano e o rural. (MONTE-MÓR, 2008). Em algum momento não há mais distinção entre o urbano e o rural. $\mathrm{O}$ tecido urbano atinge praticamente todo o território brasileiro, incluindo a região amazônica. Chega primeiramente enquanto busca de reprodução do capital, cristalizada, no caso do nosso estudo, nas políticas governamentais de ocupação e desenvolvimento da Amazônia, para depois chegar, como política, no apoio à organização da resistência indígena.

De acordo com Little (2004), já em meados de 1930 e 1940, havia um movimento de expansão em direção ao oeste paranaense, assim como em direção aos Estados de Goiás e do Mato Grosso. O autor cita também a construção de Brasília, na década de 1950, como exemplo desse movimento de expansão ao interior, levando a lugares distantes dos principais centros urbanos do país elementos sintetizados no termo moderno.

No entanto, na Amazônia, são do início da década de 1970 os maiores esforços e investimentos que visavam ocupar o território e explorar recursos. Esses investimentos partiram muitas vezes do Estado e são refletidos nos planos de desenvolvimento formulados, principalmente, pelo governo militar. Como exemplo, podemos citar o Plano de Integração Nacional (PIN), o Programa de Redistribuição de Terras e Estímulos à Agro Indústria do Norte e Nordeste (PROTERRA), o Plano Nacional de Desenvolvimento (PND), o Metas e bases para a Ação do Governo e o Primeiro Plano de Desenvolvimento Amazônico (PDA)4. (SERRA; FERNÁNDEZ, 2004). Além disso, foram construídas as estradas Belém-Brasília, Transamazônica e Cuiabá-Santarém, além de hidrelétricas (Tucuruí, Balbina Samuel) e do projeto de mineração em Carajás. (LITTLE, 2004). Houve também um esforço de atração de capital privado (via crédito e isenção fiscal), incentivando investidores que compravam latifúndios para pastagem ou especulação.

Esses projetos atraíram um grande contingente de pessoas para a região. Este processo migratório representa parte do efeito da chegada do tecido urbano e dos valores (costumes) da cidade in- 
dustrial, que também leva consigo novas atividades econômicas, novas configurações organizacionais e um novo aparato institucional $l^{5}$. Todos esses fatores são facilitados pela melhoria dos sistemas de transporte e comunicação. Porém, o processo de ocupação estimulado pelo governo acaba produzindo efeitos mais complexos do que o esperado pelos militares.

O tipo de planejamento proposto nesse período de ditadura era bastante problemático. O PIN, por exemplo, preconizava a colonização por pequenos produtores ao longo da rodovia Transamazônica ${ }^{6}$. De acordo com Schmink e Wood (2012), esta estrada não pavimentada de cerca de 5 mil $\mathrm{km}$ atraiu um grande contingente de nordestinos, que buscavam trabalho e terra, sendo que o Instituto Nacional de Colonização e Reforma Agrária (Incra) não conseguiu absorver o volume de migrantes nas terras disponíveis. Os colonos passaram a ocupar quaisquer terras, independentemente de estarem no plano do Incra (terras devolutas), tornando-se posseiros (aqueles que ocupam a terra sem título de propriedade). A disputa pelas terras mobilizou pecuaristas, agricultores, posseiros e grileiros (que possuem títulos de propriedade falsos), além dos antigos ocupantes do local, gerando uma grande onda de violência.

No início da década de 1980, por exemplo, representantes do setor privado reivindicavam seus interesses argumentando que poderiam promover uma ocupação mais eficiente do que os colonos, beneficiados pelas políticas anteriores, como o PIN, e que supostamente careciam de capacidade gerencial. Um posicionamento que, claramente, como afirmam Schimink e Wood (2012), desconsidera a falta de apoio dada aos mesmos após o repasse de terras. A pressão do setor privado foi atendida em políticas específicas dentro do segundo Plano Nacional de Desenvolvimento. A proposta era gerar polos de crescimento através do redirecionamento de investimentos (especialmente pecuária, agricultura e mineração) para regiões de maior potencial econômico. (SCHIMINK; WOOD, 2012).

Durante essa disputa, as ameaças à população indígena cresceram exponencialmente, fruto deste progresso levado às áreas mais remotas do país. As comunidades indígenas viram não só suas terras serem perdidas para empreendimentos do governo e para fazendeiros, mas também sua própria existência ser colocada em risco. Segundo Heck, Loebens e Carvalho (2005), existiu, por parte do governo militar, a intenção de exterminar os índios do país até o ano 


\section{URBANIZAÇÃO EXTENSIVA NA AMAZÔNIA BRASILEIRA E FORMAÇÃO DO MOVIMENTO INDÍGENA}

de 1988. Um documento da Conferência Nacional dos Bispos do Brasil, de dezembro de 1973, denuncia a calamitosa situação em que se encontravam os índios, amparados de maneira muito falha pela recém-criada Fundação Nacional do Índio (FUNAI). (CONFEDERAÇÃO NACIONAL DOS BISPOS DO BRASIL, 1973). Segundo os autores, uma das táticas era esconder as comunidades indígenas da população brasileira não-indígena, de modo a impedir que suas denúncias e o conhecimento do real efeito das políticas desenvolvimentistas chegassem a eles, assim como ao exterior.

$\mathrm{Na}$ esteira desses acontecimentos, os órgãos indigenistas oficiais, como a FUNAI, passavam a gozar de cada vez menor credibilidade, o que abria espaço para outros atores ocuparem o papel de reivindicação dos direitos indígenas, como o Conselho Indigenista Missionário (CIMI). Desde o período imperial, a igreja católica manteve uma relação de bastante proximidade com grupos indígenas. Posteriormente, em meados da década de 1970, teve um papel fundamental ao auxiliar a articulação dos grupos indígenas para que esses pudessem formar uma resistência consistente às crescentes ameaças. (BITTENCOURT, 2000).

O Estatuto do Índio, de 1973, foi uma tentativa de o governo militar amenizar sua imagem de violador de diretos humanos. Ele continha dispositivos que permitiam proteger as terras indígenas e garantir assistências. No entanto, segundo Albert (1991), o texto apresentava também uma série de disposições que lesavam os índios, e perpetuavam a lógica de ocupação territorial e econômica dos militares.

Nesse contexto, é iniciado o processo de união entre os índios em prol da luta contra a violação de seus direitos. A primeira Assembleia Indígena, como mostram Heck, Loebens e Carvalho (2005), ocorreu em abril de 1974, na cidade de Diamantino, no Mato Grosso. Esta e outras assembleias eram organizadas pelo CIMI, principalmente no território amazônico. Apesar de, por serem organizadas por atores não-indígenas, as Assembleias terem um caráter indigenista, elas foram os primeiros esforços para que se gerasse um maior protagonismo do índio em relação às suas demandas frente ao Estado. O propósito dessas assembleias era de que os índios se conhecessem, conversassem, dando os primeiros passos em direção à superação de todo paternalismo $\left(1^{\mathrm{a}}\right.$ ASSEMBLÉIA DE CHEFES INDÍGENAS, p. 1 apud BICALHO, 2010a). 
Entre os anos 1970 e 1980 ocorreram quinze Assembleias Indígenas, que tiveram papel crucial de mobilização de base. (BICALHO, 2010b) ${ }^{7}$. Nesse período, alguns líderes indígenas começam a sair de suas comunidades em busca de apoio, gozando da vantagem de esse tipo de organização não ser alvo de repressão tão direta como eram os movimentos operários ${ }^{8}$.

Ainda em 1978, o governo tenta a emancipação dos índios, deixando-os à própria sorte para lidarem com as ameaças das incursões brancas em seus territórios. Esses acontecimentos serviram de grande fomento para o aumento da organização indígena e pró-índios. (RAMOS, 1995). Embalados pelo sucesso de seus protestos, que engavetou aquela tentativa do Presidente Geisel de emancipação dos indígenas, fundou-se a União das Nações Indígenas (UNI), com participação de 32 etnias. Essa organização nasce de um Seminário, em 1980, em Campo Grande/MT, que contou com um importante protagonismo indígena, apesar das tentativas de emparelhamento da FUNAI e do governo do estado. (DEPARIS, 2007).

A UNI se tornou grande representante dos povos indígenas, dando voz a suas demandas junto às entidades governamentais, e sendo muito importante nas conquistas posteriores, principalmente nas campanhas em relação à constituinte de 1988. Neste último caso, em particular, como aponta Verdum (2009), vale ressaltar a inserção de um capítulo na Constituição Federal (CF) que se intitulava Dos Índios. Apesar da relevância do fato, este se limitou a alguns direitos específicos, sem conseguir mover as políticas públicas do país na direção do reconhecimento do país como um Estado multicultural. (VERDUM, 2009).

Nesse processo de disputa das comunidades indígenas contra os braços estatal e privado do capitalismo, teve papel central o modo de ocupação da terra. Os direitos de propriedade comum de terra, estatal e privado, típicos de comunidades indígenas e de algumas comunidades camponesas, foram desconsiderados, assim como as tentativas de proteção ambiental, de delimitação das terras indígenas, ou de defesa de direitos de pequenos produtores. Como apontam Schmink e Wood (2012), a defesa desses tópicos costumava inclusive ser rotulada como subversiva, o que resultava inclusive em casos de aprisionamento, torturas e assassinatos cometidos pela ditadura militar. Quando vindas do exterior, as mesmas propostas eram tidas como propaganda imperialista. 


\section{URBANIZAÇÃO EXTENSIVA NA AMAZÔNIA BRASILEIRA E FORMAÇÃO DO MOVIMENTO INDÍGENA}

Os autores ainda argumentam a existência de um corolário implícito no pensamento desenvolvimentista. Este incluía considerar quaisquer atividades de pequenos agricultores como ineficientes, os camponeses como inferiores, e, como baixo, o valor econômico e biológico da floresta Amazônica (resumida à potencialidade da venda de madeiras nobres). Além disso, era clara a desvalorização, em geral, de técnicas e da cultura indígena. (SCHMINK; WOOD, 2012).

Próximo ao fim da ditadura, no entanto, além da atuação dos militares na Amazônia já estar enfraquecida, as críticas internacionais estavam mais intensas e frequentes. Camponeses, garimpeiros, indígenas e seringueiros buscavam se organizar e enfrentar os grandes investidores. Isso se concretizou, em parte, em 1982, quando Mario Juruna se tornou o primeiro (e único) índio eleito deputado federal na história do País. No entanto, esta conquista não impediu que, em 1983, fosse editado um decreto que dificultava demarcação de terras indígenas, envolvendo vários ministérios no processo decisório. Ainda em 1983 ocorre mais um retrocesso para a causa indígena: um decreto permite mineração nas terras indígenas sob supervisão da FUNAI. Em 1987, já após o fim da ditadura, o processo de demarcação ganha um novo obstáculo, com a entrega da coordenação dos processos ao Ministério do Interior, e não à FUNAI. (SCHMINK; WOOD, 2012).

A Constituição de 1988 foi, de fato, um avanço significativo para os Movimentos Indígenas, no entanto, não suficiente para garantir seus direitos, que são mais ameaçados à medida que avança a ocupação capitalista de suas terras. Exemplos de iniciativas tomadas após a redemocratização que não se diferenciaram essencialmente das políticas anteriores são: o Programa Calha Norte (que previa que o exército estabeleceria colônias militares ao longo das regiões de fronteira e melhoraria o sistema de transporte na região norte) e o Projeto Carajás. Como apontam Schmink e Wood (2012), as políticas indigenistas do governo brasileiro mantiveram a característica de serem diametralmente opostas aos interesses dos povos indígenas. A grande modificação foi apenas no contexto em como as disputas agora se dão e seus resultados, causados pela inclusão de outros atores, com a mídia nacional e internacional tendo papel de destaque. Ainda assim, Little (2004, p. 269) aponta para a importância dos avanços políticos dos indígenas, com a organização interna de sua sociedade, como um ponto de avanço que foi possibilitado 
pela constituição de 1988. Segundo o autor, isso deu início a um "[...] processo administrativo de delimitação, demarcação física, homologação e registro." que durou toda a década de 1990.

A partir desse período o número de associações e organizações indígenas cresceu de maneira acelerada, seja para a defesa de interesses assistenciais, comerciais, de demarcação de território ou de questões internas. De acordo com o Instituto Socioambiental (ISA) ${ }^{9}$, hoje, apenas no estado do Amazonas, já estão estabelecidas mais de 160 delas. Segundo o instituto, foi a constituição de 1988 que possibilitou esse ocorrido, ao permitir que essas associações fossem constituídas como pessoas jurídicas. (INSTITUTO SOCIOAMBIENTAL, [20--?]). Além disso, ainda existe uma série de organizações de defesa dos direitos dos indígenas dirigidas por não-indígenas, como o próprio ISA, assim como uma transnacionalização do movimento a partir de organizações locais, como mostra Brysk (1996).

Assim, como resposta às mudanças impostas especialmente a partir da década de 1970, o movimento indígena se articula e se fortalece buscando condições de defender seus direitos ameaçados. Especificamente na Amazônia, além do surgimento de novos atores sociais em disputa pela terra, a presença do Estado coloca para os movimentos a necessidade de se posicionar em torno de uma opção de projeto de desenvolvimento para a região, que determina o caráter da intervenção governamental. Esse movimento pode ser entendido como um segundo momento da urbanização extensiva, discutida no começo da sessão. Na próxima seção buscamos compreender melhor como se dá essa reação dos movimentos indígenas.

\section{POLITIZAÇÃO DO ESPAÇO NA AMAZÔNIA}

Primeiramente, vale esclarecer que falar em politização do espaço na Amazônia não significa ignorar as formações políticas que precedem a ocupação promovida no período da ditadura militar no Brasil. Especialmente sobre as comunidades indígenas, foco deste trabalho, há uma organização política bastante característica, e de modo geral bastante diferente da proposta pelo modelo de estado nacional que chega através da explosão do tecido urbano.

No modelo de estado nacional, as fundações do pensamento político estão nas ideias de legitimidade, representação e unidade. Os líderes se legitimam de alguma forma (seja através do voto po- 
pular, ou de algum discurso que justifique a violência das ditaduras), e tomam para si a tarefa de representar a sociedade. O estado pressupõe uma unidade nacional, uma vez que, em teoria, representa a totalidade da população e não só aqueles que se declaram de acordo com as decisões tomadas.

Porém, o que os antropólogos notam nas comunidades indígenas somente pode ser entendido se abrimos mão daquelas categorias como fundadoras de qualquer sistema político, conforme sugerido por Clastres (1974). Ao discutir o assunto, e pensando mais especificamente nos povos amazônicos contemporâneos, durante seminário promovido pelo Instituto Socioambiental, Viveiros de Castro reforça o argumento de que as comunidades muitas vezes não representam um coletivo no sentido em que estamos habituados a pensar (marcado pelas ideias de Estado, representação, legitimidade, etc). (LIMA; BENSUSAN, 2003)

Não é o objetivo deste texto entrar em detalhes sobre aqueles sistemas políticos. Interessa-nos, aqui, refletir como os povos indígenas dialogam, no contexto de ameaça territorial (e de outras formas de violência), com o estado nacional, buscando o reconhecimento e a garantia de seus direitos.

Nesse sentido, Secchi (2007) propõe uma periodização para compreender as etapas através das quais se desenvolve esta relação com o estado. Para o autor, até a década de 1970, as políticas voltadas para as comunidades indígenas praticamente não contavam com seu envolvimento, a não ser como observadores ou prestadores de serviço. Isso começa a mudar entre os anos 1970 e 1980, período marcado pela atuação do Serviço de Proteção ao Índio (SPI), criado ainda em 1910, e pelas políticas de integração nacional e desenvolvimento do Centro-Oeste e da Amazônia.

No entanto, ainda assim, as políticas públicas para as comunidades indígenas muitas vezes eram resultado de exigências para a liberação de recursos de empréstimo internacional feitos por certas entidades estrangeiras, ou, em outros momentos, limitadas às migrações das comunidades para fim de realocação por eventual construção de estradas ou hidrelétricas. Já nos anos 1990, inicia-se a preocupação com valores étnicos, culturais e de cidadania dos índios. Aqui os projetos vão, desde o apoio à demarcação territorial, até a educação escolar e o fortalecimento institucional. 
Esse modelo de política pública representa um grande avanço em relação aos períodos anteriores, porém ainda mantém a limitação de ser concebido, elaborado e avaliado segundo os critérios das agências financiadoras e/ou das equipes técnicas não-indígenas. São políticas que contam apenas com a participação indígena. (SECCHI, 2007, p. 18).

Atualmente, as políticas públicas para comunidades indígenas são gradativamente entendidas como partes integrantes dos Planos de Vida das mesmas. Espera-se que os indígenas possam tomar o papel de protagonistas, definindo prioridades, elaborando os projetos, planejando, acompanhando e avaliando.

Com relação a isso, desde meados de 1970 o movimento indígena vem se articulando e se fortalecendo, buscando condições de defender seus direitos ameaçados. Especificamente na Amazônia, além do surgimento de novos atores sociais em disputa pela terra, a presença do Estado coloca para os movimentos a necessidade de se posicionarem em torno de uma opção de projeto de desenvolvimento para a região, que determina o caráter da intervenção governamental. O surgimento e a politização do Movimento Indígena são, portanto, uma resposta ao processo de urbanização extensiva, num primeiro momento, mas são também construídos, alimentados e possibilitados a partir deste processo. A maior mobilidade e comunicação entre as lideranças e etnias indígenas possibilitam uma ação conjunta destes atores, criando possibilidades para que suas demandas fossem consideradas.

Outro aspecto de destaque no movimento indígena é que o discurso adotado (não só pelos indígenas, como também por outros grupos tal como os seringueiros), amparado na preservação ambiental e cultural, não é um discurso originalmente amazônico. Embora as pautas sejam legítimas e tenham sua importância verdadeiramente considerada por aqueles que utilizam este discurso, esses temas nunca haviam sido utilizadas como ativo político. Até mesmo Chico Mendes, em entrevista pouco anterior a seu assassinato, como lembram Schmink e Wood (2012), apontava para a novidade que a palavra ambiente significava para o vocabulário dos seringueiros.

A explosão do tecido urbano e o fluxo de relações e informações que ela traz possibilitaram ao movimento indígena o contato com grupos de ambientalistas, antropólogos e ativistas de um modo geral, tanto brasileiros quanto estrangeiros. Deste contato, apropriam-se, os indígenas, de um novo vocabulário político, que 


\section{URBANIZAÇÃO EXTENSIVA NA AMAZÔNIA BRASILEIRA E FORMAÇÃO DO} MOVIMENTO INDÍGENA

embora seja povoado por elementos amazônicos e distantes da figura caricata da cidade (a natureza, o conhecimento tradicional, etc) somente é traduzido para o discurso político através do contato com o urbano.

Cunha (2009) discute a formação de novas estratégias políticas na Amazônia para lidar com ameaças territoriais. Para a autora, tudo mudou quando as comunidades perceberam o poder argumentativo da identidade e da preservação ambiental. Assim, a estratégia política passa a ser provar que se tem cultura, e, sobretudo, uma cultura preservacionista. Além da apropriação da ideia de ambientalismo, podemos destacar também a definição de uma nova categoria social: a comunidade tradicional, que poderia ser definida como

$$
\begin{aligned}
& \text { [...] grupos que conquistaram ou estão lutando para conquistar } \\
& \text { (prática e simbolicamente) uma identidade pública conservacionis- } \\
& \text { ta que inclui algumas das seguintes características: uso de técnicas } \\
& \text { ambientais de baixo impacto, formas equitativas de organização } \\
& \text { social, presença de instituições com legitimidade para fazer cum- } \\
& \text { prir suas leis, liderança local e, por fim, traços culturais que são se- } \\
& \text { letivamente reafirmados e reelaborados. (CUNHA, 2009, p. 300). }
\end{aligned}
$$

Este termo tem uma importância política estratégica uma vez que, juridicamente ser reconhecida como comunidade tradicional é um passo decisivo na conquista de direitos, sem, no entanto, significar que as comunidades estivessem adotando uma identidade ilegítima somente pelas vantagens que esta pode trazer. Nesse sentido, Cunha (2009) ressalta que embora a aliança conservacionista feita entre as comunidades locais e atores externos fosse uma estratégia política, isso não significa que a intenção de preservar fosse falsa. A autora explica que o compromisso dessas populações com a conservação pode ser, em certa medida, uma projeção ocidental de preocupações ecológicas, uma vez que as próprias comunidades até então não haviam elaborado uma reflexão diretamente sobre o assunto. $\mathrm{O}$ que não significa, porém, que a importância da preservação não estivesse sendo considerada na prática já há muitos anos pelos locais.

Segundo a autora, há três tipos de ambientalismo. A ideologia sem prática, que se restringe ao apoio verbal; a prática ancorada na cosmologia, quando a exploração limitada dos recursos naturais se baseia na ideologia de que os seres humanos são os mantenedores do equilíbrio do universo, que inclui tanto a natureza como a sobrenatureza; e a prática sem ideologia, na qual os hábitos e regras 
são compatíveis com a sustentabilidade, mas não se justificam em nenhum compromisso moral. (CUNHA, 2009, p. 288).

Assim, a preservação ambiental já faz parte da prática dos povos amazônicos, mesmo que nem sempre ancorada em uma ideologia correspondente. Essa é posteriormente transformada em discurso político por sujeitos dispostos a conferir-lhe substância através de seu comprometimento com o pacto conservacionista, em troca de algum ganho político e de direitos.

O mesmo ocorre com a noção de cultura. Enquanto a antropologia contemporânea vem tentando se desfazer da noção de cultura, vários povos estão mais do que nunca celebrando sua cultura e utilizando-a para obter reparações por danos políticos. Assim, este conceito importado do que é a cultura assume papel de argumento político, levando seus possuidores a demonstrá-la performaticamente. (CUNHA, 2009). Surge assim uma questão: quais são os processos, as questões e as transformações implicadas no ajuste e na tradução da categoria importada de cultura? Para a autora, fazer com que as coisas permaneçam exatamente iguais àquilo que demanda um esforço não espontâneo, já que a dinâmica cultural, se for deixada por sua própria conta, provavelmente fará com que as coisas pareçam diferentes. A mudança, nesse caso, se manifesta no esforço para permanecer igual.

A partir dessa necessidade de fazer uma performance cultural, trazendo a público uma cultura estática que não corresponde à realidade da cultura, que é dinâmica e se alimenta inclusive do contato com os valores urbano-industriais trazidos pela urbanização extensiva, Cunha (2009) identifica uma relação que se estabelece entre a cultura e a cultura.

A cultura seria essa que se forja a partir de sua função política, e a cultura, aquela que de fato existe, dinâmica e que nunca fora antes pensada pelas populações, não sendo, portanto, uma categoria conceitual própria. Para a autora, uma influencia a outra ininterruptamente. Assim, a cultura é produzida a partir da cultura, que por sua vez é influenciada pela forma como é representada neste momento performático. Assim, após a representação da cultura a própria cultura se modifica, de modo que a próxima representação se dará com base em novos termos, nos termos recentemente apropriados por uma cultura em constante transformação. O mesmo ocorre com os atores envolvidos nos processos que estamos tratando e suas rei- 

MOVIMENTO INDÍGENA

vindicações. Ao entendê-las como fruto das posições ideológicas, Schmink e Wood (2012, p. 56) argumentam que elas não devem ser entendidas apenas como reflexos dos interesses materiais, tampouco meras "[...] características estáticas da consciência das pessoas". Sua abordagem trata da ideologia como algo a ser criado e utilizado como modo de influenciar o discurso aceito.

\begin{abstract}
Nesse processo, eles vão também modificando a maneira como definem a si próprios, e seu entendimento sobre o mundo a sua volta. A ação desses atores sociais, portanto, tem uma propriedade constitutiva, isto é, as preferencias, interesses e ideias que definem indivíduos - e que se tornam uma base para a ação coletiva - são formadas ou constituídas nas ações concretas de uma disputa. (SCHMINK; WOOD, 2012, p. 56).
\end{abstract}

Sendo assim, a ação de grupos e indivíduos não tem como função apenas o alcance de uma finalidade conhecida, mas também a própria formação. Esse entendimento torna os interesses dinâmicos, sempre sujeitos à redefinição a partir do contato com outros interesses e o discurso mais aceito, que também estão em constante modificação.

Com isso, as disputas políticas, além de seus resultados imediatos, causam também modificações no contexto em que os conflitos locais subsequentes se realizarão. $\mathrm{O}$ que se argumenta é que o processo descrito foi iniciado pela chegada do tecido urbano, como explicitado anteriormente. Um dos resultados inesperados do amadurecimento do movimento indígena e de suas transformações a partir do contato intenso com os valores urbano-industriais é o surgimento dos movimentos compostos exclusivamente por mulheres, onde há uma primeira impulsão trazida pela polis, que posteriormente, em um momento de maior autonomia desses movimentos, vai resultando na cultura, permeada cada vez mais pela cultura, que em processo recíproco é também modificada pelos próprios desenvolvimentos e pela experiência vinda dos movimentos.

$\mathrm{O}$ surgimento das associações de mulheres indígenas ${ }^{10}$ se dá primeiramente em ambiente urbano, muito ligado às condições de vida dessas mulheres nas cidades, como a Associação de Mulheres Indígenas do Alto do Rio Negro (AMARN) e a Associação de Mulheres Indígenas Sateré-Maué (AMISM) - duas das primeiras organizações criadas - graças ao grande número de mudanças de famílias das aldeias para a cidade. (SANTOS, 2012). 
Essas associações são criadas como uma tentativa de sobrevivência no mundo urbano, em um sentido de associativismo comercial de mulheres indígenas necessitadas de assumirem o papel de provedoras de suas famílias, muitas vezes ancoradas em trabalhos artesanais. Esse movimento pressiona, ligeiramente, uma melhor distribuição de tarefas entre os gêneros, segundo Matos (2012). Essas primeiras associações tinham como características problematizar assuntos que diziam respeito a ambos os gêneros, no entanto, a partir da perspectiva feminina (terra, educação, renda, etc.). Em um segundo momento é que as mulheres indígenas passam a formular demandas específicas de seu gênero para a organização de seus movimentos.

Dois grandes avanços para os movimentos de mulheres indígenas foram a criação de departamentos de mulheres indígenas, em várias organizações de indígenas da Amazônia Brasileira, a partir de 2002, e a posterior criação da União das Mulheres Indígenas da Amazônia Brasileira (UMIAB), em 2009 ${ }^{11}$. (MATOS, 2012). Esses foram parte importante para o protagonismo da mulher indígena dentro do movimento indígena.

Apesar dos avanços na questão de gênero, de um modo geral, os direitos indígenas têm sofrido sucessivos ataques nos últimos anos. Durante os governos da presidenta Dilma Roussef, o reconhecimento das Terras Indígenas (TIs) foi feita de maneira bastante lenta. Segundo dados levantados pelo ISA, apenas 21 TIs foram homologadas, 25 TIs foram declaradas e 44 TIs foram identificadas e delimitadas.

Além disso, a FUNAI foi fragilizada, tendo, em cinco anos, cinco presidentes, dois deles interinos. Houve também denúncias de que o órgão estava sendo impedido de realizar suas funções (INSTITUTO SOCIOAMBIENTAL, 2016). Uma das razões para esta fragilização é a aliança que o governo mantinha com a bancada ruralista, que pressionava pela paralisação de quaisquer avanços na pauta dos direitos indígenas, que ficaram à mercê de negociações políticas. Para o antropólogo Luis Donizete Benzi Grupioni, da Rede de Cooperação Amazônica (RCA), Dilma rifou os direitos dos índios:

Sua concepção atrasada de desenvolvimento e justiça social alimentou uma velha concepção de que índios e meio ambiente são entraves para o progresso e um problema para as grandes obras de infraestrutura. Pouco se fez para conter a violência contra os povos 


\title{
URBANIZAÇÃO EXTENSIVA NA AMAZÔNIA BRASILEIRA E FORMAÇÃO DO MOVIMENTO INDÍGENA
}

\author{
indígenas, que atingiu níveis de barbárie em certas regiões do país. \\ Tratou o direito de consulta como mera formalidade burocrática \\ e usou e abusou de entulho da época militar, ao lançar mão do \\ instrumento de suspensão de liminar para consumar empreendi- \\ mentos mal planejados em fatos consumados e não consultados. \\ (INSTITUTO SOCIOAMBIENTAL, 2016)
}

$\mathrm{O}$ afastamento da presidenta não fez com que o cenário mudasse, pelo contrário. Ao assumir, o presidente interino Michel Temer já mencionou sua intenção de revisar as portarias declaratórias e decretos de homologação de Terras Indígenas publicados ao final do Governo Dilma Rousseff. Logo foi elaborada uma proposta que alteraria o rito de demarcação de terras indígenas, restringindo os direitos territoriais indígenas e disponibilizando suas terras para empreendimentos econômicos.

Como reação, mais de 130 organizações como a Articulação dos Povos Indígenas do Brasil (APIB), o Movimento dos Trabalhadores Rurais Sem Terra (MST), Central Única dos Trabalhadores (CUT), Greenpeace, Movimento Nacional de Direitos Humanos e Associação Brasileira de ONGs (Abong) se posicionaram contra as mudanças propostas, e o governo optou por recuar. (INSTITUTO SOCIOAMBIENTAL, 2017). A situação da FUNAI também piorou com a posse de Temer, que sugeriu a indicação de ex-general da ditadura militar para a presidência do órgão. Diante da reação dos movimentos sociais, o governo recuou novamente, indicando Antônio Fernandes Toninho Costa, conhecido por ser aliado da bancada ruralista. (INSTITUTO SOCIOAMBIENTAL, 2017).

Os episódios contemporâneos da disputa entre as comunidades indígenas e representantes do capital, seja seu braço privado ou estatal, mostra como mesmo os parcos avanços de suas lutas continuam ameaçados. Esse é um processo dinâmico, principalmente ao se levar em conta que o modo de reprodução do capital está em constante modificação, sendo assim, do mesmo modo estão suas formas de apropriação do espaço e do excedente. Um grande número dos índios brasileiros já se encontra em permanente convivência com essa lógica urbano-industrial, e encontra nessa mesma lógica, como mostrado aqui, parte dos mecanismos necessários para a disputa pelo que entende como seus direitos. 


\section{CONCLUSÃO}

As lutas travadas pelas comunidades indígenas, tratadas ao longo desse trabalho, foram iniciadas a partir do confronto com valores e interesses típicos de uma lógica urbano-industrial, trazidos pela expansão do tecido urbano, e analisadas aqui através da ideia de urbanização extensiva. A teoria de Monte-Mór (2006) nos é importante para identificar os novos elementos que modificam a vida e a política das aldeias como advindas desse elemento estranho às comunidades. No entanto, essa nova forma de relacionar politicamente não se dá enquanto uma absorção cultural passiva, mas envolve também uma apropriação estratégica feita a partir da maior compreensão destes valores e interesses, que, posteriormente, negará algumas de suas características e propostas. Assim, o foco na preservação ambiental e de valores culturais é fruto da compreensão de que estas são pautas importantes no novo cenário político dos brancos, mas que por outro lado é também uma fragilidade, uma vez que existe como reivindicação, mas não ainda como direito. Essa é uma pauta que já está formulada, esperando por uma pressão mais legítima (de populações que estão cotidianamente construindo e sendo construídos a partir de sua interação com a floresta) para ser juridicamente reconhecida.

Apesar da aparente melhora conquistada pelos movimentos indígenas, que demonstram claro amadurecimento, é preciso ressaltar que as lutas não se tornaram mais fáceis, ou que essas comunidades recebem tratamento devido por parte das instâncias de poder estatal (assim como por parte dos representantes privados do capital). O Estado segue impondo seu projeto desenvolvimentista, e o capital privado, interessado em negócios como a mineração e a geração de energia, segue sendo uma ameaça. A legislação brasileira segue com brechas perigosas para os povos tradicionais que têm o processo de demarcação de suas terras, um dos seus direitos mais fundamentais, ocorrendo de forma lenta e em desacordo com as reivindicações desses povos.

Finalmente, este trabalho tratou de parte das complexas questões que surgem com o avanço da lógica urbana sobre as comunidades indígenas, tendo citado outras que requerem um espaço aprofundado de discussão. Um exemplo disso é a questão do gênero na aldeia, e como esta é afetada pelo processo por nós abordado. Nesse caso, a apropriação de discursos extrapola as questões aqui tratadas, 
URBANIZAÇÃO EXTENSIVA NA AMAZÔNIA BRASILEIRA E FORMAÇÃO DO MOVIMENTO INDÍGENA

atingindo outras pautas tais como os direitos das mulheres e as questões de gênero. Em contextos tão diferentes, seria interessante fazer uma investigação mais profunda sobre como poderia ser possível o diálogo entre o movimento feminista, marcado por um histórico de lutas influenciadas por imposições do capitalismo, da moral cristã, etc., e um movimento nascente de mulheres indígenas que pode ter pautas próprias e pautas pensadas a partir da conexão com esse movimento feminista advindo da lógica urbana.

\section{REFERÊNCIAS}

ALBERT, B. Terras indígenas Política ambiental e geopolítica militar no desenvolvimento da Amazônia: a propósito do caso Yanomami. In: LÉNA, P.; OLIVEIRA, A. E. de (Orgs.) Amazônia: a fronteira agrícola 20 anos depois. Belém: Museu Paraense Emílio Goeldi, 1991. p. $37-58$.

BARBIERI, A. F.; MONTE-MÓR, R. L.; BILSBORROW, R. E.

Towns in the jungle: exploring linkages between rural-urban mobility, urbanization and development in the Amazon. In: SHERBINIIN, A. de et al. (Eds.). Urban population-environment dynamics in the developing world: case studies and lessons learned. Paris: CICRED, 2009. p. 247-280.

BICALHO, P. S. dos S. As Assembleias Indígenas: o advento do Movimento Indígena no Brasil. Revista OPSIS, Catalão, v. 10, n. 1, p. 91-114, 2010a.

Protagonismo Indígena no Brasil: Movimento, Cidadania e Direitos (1970-2009). 2010. 464 f. Tese (Doutorado em História) Universidade de Brasília, Brasília, DF, 2010b.

BITTENCOURT, L. B. O movimento indígena organizado na América Latina: a luta para superar a exclusão. In: ENCONTRO DA ANPHLAC, 4., 2000, Salvador. Anais... Salvador: ANPHLAC, 2000.

BRYSK, A. Turning Weakness into Strength: The Internationalization of Indian Rights. Latin American Perspectives, vissue 89, v. 23, n. 2, p. 38-57, 1996.

CLASTRES, P. A Sociedade contra o Estado. São Paulo: Ed. Cosac \& Naify, 1974.

CONFEDERAÇÃO NACIONAL DOS BISPOS DO BRASIL.

Y-Juca-Pirama: o índio - aquele que deve morrer. Brasília, DF:

Documento de Urgência do Bispos Missionários, 1973. Disponível 
em: $<$ http://issuu.com/porantim/docs/120823131 950-87492f2fd eed452da6721d1 cb19b9 d17>. Acesso em: 31 dez. 2014.

CUNHA, M. C. da. Cultura com Aspas. São Paulo: Ed. Cosac \& Naify, 2009.

DEPARIS, S. R. União das Nações Indígenas (UNI): contribuição ao Movimento Indígena no Brasil (1980-1988). 2007. 126 f. Dissertação (Mestrado em História) - Universidade Federal da Grande Dourados, Dourados, 2007.

FRANÇA, S. Processo de ocupação da Amazônia e suas estratégias de integração, desenvolvimento e segurança. Revista Múltipla, Brasília, DF, v.10, n. 18, p. 137-161, 2005.

FURTADO, C. Introdução ao desenvolvimento: enfoque histórico estrutural. 3. ed. São Paulo: Ed. Paz e Terra, 2000.

. O mito do desenvolvimento econômico. 4. ed., Rio de Janeiro: Paz e Terra, 1974.

HECK, E.; LOEBENS, F.; CARVALHO, P. D. Amazônia Indígena: Conquistas e Desafios. Estudos Avançados, São Paulo, v.19, n. 53, p. 237-255, 2005.

INSTITUTO SOCIOAMBIENTAL. Entre o improviso e a maldade: a política (anti) indigenista do Governo Temer. São Paulo, 2017. Disponível em: $<$ https://www.socio ambiental.org/pt-br/noticiassocioambientais/o-que-o-governo-dilma-fez-e-nao-fez-para-garantir-odireito-a-terra-e-areas-para-conservacao $>$. Acesso em: 25 jan. 2017.

. Lista de organizações. Povos Indígenas no Brasil, [20--?]. Disponível em: $<$ https://pib.socioambiental.org/pt/c/iniciativasindigenas/organizacoes-indigenas/lista-de-organizacoes $>$. Acessado em: 02 jan. 2015.

. O que o governo Dilma fez (e não fez) para garantir o direito à terra e áreas para conservação? São Paulo, 2016. Não paginado. Disponível em: $<$ https://www.socioambiental.org/pt-br/noticiassocioambientais/o-que-o-governo-dilma-fez-e-nao-fez-para-garantir-odireito-a-terra-e-areas-para-conservacao>. Acesso em: 25 jan. 2017.

LIMA, A.; BENSUSAN, N. Quem cala consente?: subsídios para a proteção aos conhecimentos tradicionais.. São Paulo: Instituto Socioambiental, 2003. (Documentos ISA, n. 8)

LITTLE, P. Territórios Sociais e Povos Indígenas no Brasil: por uma antropologia da territorialidade. Anuário Antropológico 2002/2003, Rio de Janeiro, p. 251-290, 2004. 

MOVIMENTO INDÍGENA

MATOS, M. H. O. Mulheres no movimento indígena: do espaço de complementariedade ao lugar da especificidade. In: SACCHI, A.; GRAMKOW, M. (Orgs.). Gênero e povos indígenas. Rio de Janeiro; Brasília, DF: Museu do Índio-FUNAI, 2012. p. 140-171.

. O processo de criação e consolidação do movimento PanIndígena no Brasil (1970-1980). 1997. Dissertação (Mestrado em Antropologia) - Universidade de Brasília, Brasília, DF, 1997.

MONTE-MÓR, R. L. O que é o urbano no mundo contemporâneo. Revista Paranaense de Desenvolvimento, Curitiba, n. 111, p. 9-18, 2006.

Urbanização Extensiva e Economia dos Setores Populares. In: OLIVEIRA, M. P.; COELHO, M. C. N.; CORREA, A. de M. (Orgs.). O Brasil, a América Latina e o Mundo: espacialidades contemporâneas. Rio de Janeiro: Lamparina, Faperj, Anpege, 2008. p. $128-140$

RAMOS, A. R. O índio hiper-real. Revista Brasileira de Ciências Sociais, São Paulo, v. 28, n. 10, p. 5-14, 1995.

SACCHI, A. Mulheres indígenas e participação política: a discussão de gênero nas organizações de mulheres indígenas. Revista Anthropológicas, Recife, ano 7, v. 14, p. 95-110, 2003.

SANTOS, F. V. dos. Mulheres Indígenas, Movimento Social e Feminismo na Amazônia: Empreendendo aproximações e distanciamentos necessários. Revista EDUCAmazônia - Educação Sociedade e Meio Ambiente, Humaitá, ano 5, v. 8, p. 94-104, jan./jun. 2012.

SCHMINK, M.; WOOD, C. Conflitos sociais e a formação da Amazônia. Belém: EDUFPA, 2012.

SECCHI, D. Autonomia e Protagonismo Indígena nas Políticas Públicas. Cadernos de Educação Escolar Indígena - PROESI, Barra do Burges, v. 5, n. 1, p. 11-20, 2007.

SERRA, M. A.; FERNÁNDEZ, R. G. Perspectivas de desenvolvimento da Amazônia: motivos para o otimismo e para o pessimismo. Economia e Sociedade, Campinas, SP, v. 13, n. 2, p. $107-$ 131,2004

SILVA, J. C. Neodesenvolvimentismo e comunidades quilombolas: uma questão ausente? Revista de Políticas Públicas, v. 17, n. 2, p. 4452, jul./dez. 2013. 
VERDUM, R. Povos Indígenas no Brasil: O desafio da autonomia. In: . (Org.). Povos Indígenas: Constituições e Reformas Políticas na américa Latina. Brasília, DF: Instituto de Estudos socioeconômicos, 2009. p. 91-112.

\section{NOTAS:}

1 Indigenismo é o pensamento sobre os índios feito pelos não índios, como aponta Bittencourt (2000), enquanto o protagonismo indígena é o "[...] rompimento com as relações de tutela e submissão." (SECCHI, 2007, p. 11).

2 A autora não desconsidera os movimentos indígenas que existiram no país desde os anos quinhentista: "As revoltas, lutas, movimentos sociais nativos e resistências armadas indígenas deste passado histórico, representam fases inicias fundamentais para o processo de formação da luta social indígena no Brasil; mas não representam uma continuidade ininterrupta deste passado com o Movimento Indígena contemporâneo." (BICALHO, 2010b, p.18)

3 "Da ideia grega da polis vem o conceito de política, enquanto do latim civis e civitas vêm cidadão, cidadania, cidade e mesmo civilização.” (MONTE-MÓR, 2006, p. 6)

4 Complemento ao PND.

5 Esse processo de urbanização enquanto um padrão de desenvolvimento para o território amazônico modificou profundamente a vida da população local, algo discutido em aspectos diferentes dos pretendidos aqui em Barbieri, Mont-Mór e Bilsborrow (2009).

6 A Transamazônica, assim como a Cuiabá-Santarém, ambas parte do PIN, são consideradas um grande fracasso, resultando baixo alcance de objetivo, aumento da densidade demográfica e desenvolvimento, com incomensurável impacto ambiental. (FRANÇA, 2005).

7 A autora cita outras contabilizações, como a de Matos (1997), que aponta para a realização de cinquenta e três assembleias entre 1974 e 1984.

8 Maria Helena Ortolan Matos (2012, p. 140) resume bem a maneira como muda a configuração dos Movimentos Indígenas a partir da década de 1970: "Em sua fase inicial, assumiu caráter organizacional pan-indígena, unindo (palavra de ordem política da época) grupos étnicos distintos para obter o reconhecimento legal do direito à diferença no Estado nacional. Em sua fase de consolidação no final dos anos 1980, o movimento indígena se institucionalizou e foram criadas diversas organizações étnicas, articuladas localmente e regionalmente. Nos anos 1990, com mudanças de orientação na política indigenista do Estado brasileiro, inúmeras organizações indígenas locais e regionais foram surgindo, com distintos perfis (associações de categorias sociais e econômicas, organizações étnicas e também pluriétnicas, de caráter político ou de caráter econômico), interessadas em atuar na elaboração e gestão de projetos nas respectivas terras indígenas."

9 O ISA é uma Organização da Sociedade Civil de Interesse Público (Oscip), criada em 1994, que trabalha com direitos socioambientais.

${ }^{10}$ Para uma lista das Organizações de Mulheres Indígenas da Amazônia Brasileira que existiam no começo dos anos 2000, ver Sacchi (2003).

${ }^{11}$ A UMIAB surgiu a partir da III Conferência Nacional das Mulheres Índias, que se reuniu pela primeira vez em 2004. 